http://www.jfas.info

\title{
A REVIEW ON ELECTROMAGNETICS (EM) EXPOSURE MEASUREMENT TECHNIQUES FROM BASE STATION
}

\author{
A. R. S. N. Dianah ${ }^{1}$, S. N. Hazmin ${ }^{1, *}$, R. Umar ${ }^{2}$, M. K. A. Kamarudin ${ }^{2}$ and A. N. Dagang ${ }^{3}$ \\ ${ }^{1}$ School of Fundamental Science, Universiti Malaysia Terengganu, 21030 Kuala Terengganu, \\ Terengganu, Malaysia \\ ${ }^{2}$ East Coast Environmental Research Institute (ESERI), Universiti Sultan Zainal Abidin, Gong \\ Badak Campus, 21300 Kuala Nerus, Terengganu, Malaysia \\ ${ }^{3}$ School of Ocean Engineering, Universiti Malaysia Terengganu, 21030 Kuala Terengganu, \\ Terengganu, Malaysia
}

Published online: 08 August 2017

\begin{abstract}
EM exposure in the range of non-ionizing radiations (NIR) which falls in the radio frequency up to $3 \mathrm{GHz}$ is mainly sourced from mobile phone base stations, broadcast towers and radar facilities. This reviews based on previous researcher obtained results and methods in order to determine the best technique to measure the exposure. Moreover, the estimation of exposure levels by considering the specification of the antennas installed and area of the base stations itself was also reviewed. It was found that numerous study of NIR exposure level has been conducted in other countries, while Malaysia has become aware of the importance. Most of the studies used field meter to carry out the measurement, and the exposure level obtained were far lower than the limit recommended by World Health Organization (WHO).
\end{abstract}

Keywords: electromagnetic exposure level; base station; electric field strength; geographical information system.

Author Correspondence, e-mail: norhazmin@umt.edu.my

doi: http://dx.doi.org/10.4314/jfas.v9i2s.14 


\section{INTRODUCTION}

Mobile phone usage in the era of globalization is very significant and considered as a very important medium in everyday life at all ages. However, without public awareness, some studies proved that the long-term adverse effects from electromagnetic radiation emitted from cell phones may be occurred. Radiation emitted known as non-ionizing radiation (NIR) which refers to a type of radiation that does not have enough quantum energy to go through the process of ionization [1] resulting from the propagation of electric and magnetic waves through space at the speed of light [2]. Base station antennas give off radiation at higher power levels compared to the other types of land-mobile antennas [3]. Usually, the base station towers (BST) erected close to residential areas to provide high quality coverage in the context of Quality of Service (QoS) [4-5]. Therefore, mobile phone users like us were exposed to the both radiation sources at once [6]. Even worse, we will be exposed to this radiation in a long period as both of these sources are close to us. Public awareness on the health risks due to the exposure to RF emission has become significant. This is due to many studies have been conducted on the adverse effects of the long term exposure from the sources mentioned on the living things [7-13]. Some of them have proved that the NIR exposure has possible effects on human health. According to some of previous studies, a repetitive exposure to NIR not only can cause health effects such headaches, insomnia, dermatitis, miscarriage, cancer and other effects [11] but also can effects on reproductive system [12]. Otherwise, a few studies showed that NIR exposure does not affect or even in small risk to human health [14-19]. However, at this moment the World Health Organization (WHO) has still consider the NIR exposure will not affect human health as long as the reference limit has not been exceeded. World Health Organization (WHO) reported that exposure to RF fields such as those emitted by mobile phones and their base stations is unlikely to induce or promote cancers [20]. In 2019, about 9.3 billion of mobile telecommunication technologies subscription estimated will affect each person in the world [21].

Hence, there are a lot of national and international organizations that have been established responsible for the development of NIR exposure limits guidelines for the general public and workers. They are Institute of Electrical and Electronics Engineering (IEEE), American 
National Standard Institute (ANSI), National Council on Radiation Protection and Measurement (NCRP), Federal Communication Commission (FCC), Australian Radiation Protection and Nuclear Safety Agency (ARPANSA), National Radiation Protection Board (NRPB) and other organizations. In addition, there is also an international organization provides guidance on the health and environmental effects of NIR to protect people and the environment from detrimental NIR exposure that is known as International Commission on Non-Ionizing Radiation Protection [22-26].

Base stations emit high frequency (HF) fields in the range from several hundred $\mathrm{MHz}$ to several $\mathrm{GHz}$ (3 MHz to $300 \mathrm{GHz}$ ) [25, 39]. Meanwhile, in telecommunication services, the EM waves radiated by antennas of BST oscillates at radio frequency (RF) that is defined as the part of electromagnetic spectrum occupy the frequency range $3 \mathrm{kHz}$ to $300 \mathrm{GHz}$ [1-3] which known as RF radiation which also included in the high frequency range. The higher the frequency, the higher the energy. Thus, the farther it can penetrate the human body and further up to the body's cells. Table 1 shows transmit and receive frequency limits from base station for three types of communication systems [26].

Other than that, above a certain threshold level depending on the duration, HF exposure and following by rising temperature can trigger serious health effects such as heatstroke and burning of tissue [22-24]. The long exposure to NIR can trigger cancer cells which caused by the change in the structure of DNA and referred as thermal effect [27-28].

Therefore, many researchers have studied on radiation exposure including from the source of BST [20, 28-30]. Most of the studies are focusing on EM radiation level measurement [29], compared with regulatory of Radio Frequency-Electromagnetic Field (RF-EMF) exposure levels in the corresponding areas and are mainly concentrated on BST either indoor or outdoor around the residential area [31]. 
Table 1. Frequency limits from base station in communication systems

\begin{tabular}{|c|c|c|c|}
\hline \multicolumn{2}{|c|}{ Systems } & \multirow{2}{*}{$\begin{array}{c}\text { Lower Frequency Limits } \\
452 \mathrm{MHz}\end{array}$} & \multirow{2}{*}{$\begin{array}{c}\text { Upper Frequency Limits } \\
456.475 \mathrm{MHz}\end{array}$} \\
\hline CDMA 450 & (BaseRx) & & \\
\hline & (BaseTx) & $462 \mathrm{MHz}$ & $466.475 \mathrm{MHz}$ \\
\hline \multirow[t]{4}{*}{ EGSM/GSM } & (BaseRx) & $880 \mathrm{MHz}$ & $915 \mathrm{MHz}$ \\
\hline & (BaseTx) & $925 \mathrm{MHz}$ & $960 \mathrm{MHz}$ \\
\hline & (BaseRx) & $1710 \mathrm{MHz}$ & $1785 \mathrm{MHz}$ \\
\hline & (BaseTx) & $1805 \mathrm{MHz}$ & $1880 \mathrm{MHz}$ \\
\hline \multirow[t]{15}{*}{ IMT } & (BaseRx) & $825 \mathrm{MHz}$ & $835 \mathrm{MHz}$ \\
\hline & (BaseTx) & $870 \mathrm{MHz}$ & $880 \mathrm{MHz}$ \\
\hline & (BaseRx) & $880 \mathrm{MHz}$ & $915 \mathrm{MHz}$ \\
\hline & (BaseTx) & $925 \mathrm{MHz}$ & $960 \mathrm{MHz}$ \\
\hline & (BaseRx) & $1710 \mathrm{MHz}$ & $1785 \mathrm{MHz}$ \\
\hline & (BaseTx) & $1805 \mathrm{MHz}$ & $880 \mathrm{MHz}$ \\
\hline & (BaseRx) & $1920 \mathrm{MHz}$ & $1980 \mathrm{MHz}$ \\
\hline & (BaseTx) & $2110 \mathrm{MHz}$ & $2170 \mathrm{MHz}$ \\
\hline & (BaseRx) & $1980 \mathrm{MHz}$ & $2010 \mathrm{MHz}$ \\
\hline & (BaseTx) & $2170 \mathrm{MHz}$ & $2200 \mathrm{MHz}$ \\
\hline & (BaseRx) & $2500 \mathrm{MHz}$ & $2570 \mathrm{MHz}$ \\
\hline & (BaseTx) & $2620 \mathrm{MHz}$ & $2690 \mathrm{MHz}$ \\
\hline & TDD & $1885 \mathrm{MHz}$ & $1920 \mathrm{MHz}$ \\
\hline & TDD & $2010 \mathrm{MHz}$ & $2025 \mathrm{MHz}$ \\
\hline & TDD & $2570 \mathrm{MHz}$ & $2620 \mathrm{MHz}$ \\
\hline
\end{tabular}

Note: TDD-Time Division Duplex

\section{EM MEASUREMENT FACTORS}

\subsection{Unit Conversion of Field Strength}

The electromagnetic field (EMF) generated from two fields; electric field and magnetic field. Since these fields are believed harmful for human health as long as to living things, the field 
strength is the important factor to be concerned of. The EMF strength value is essential to determine the amount of radiation emitted from a radiation source such as base station, electric power lines, home electrical appliances and many more. Furthermore, it is also necessary to make sure that the exposure levels received are not exceeding the limit suggested by the government and the International Radiation Protection Association (IRPA).

The electric field (EF) strength relative to 1 microvolt per meter $(\mathrm{dB} \mu \mathrm{V} / \mathrm{m})$ can be converted from the value of voltage relative to 1 microvolt $(\mathrm{dB} \mu \mathrm{V})$ using the formula below [27].

$\mathrm{E}=\mathrm{AF}+\mathrm{V}(\mathrm{dB} \mu \mathrm{V})+\mathrm{L}$

Where $\mathrm{E}=$ Electric field strength, $\mathrm{dB} \mu \mathrm{V} / \mathrm{m}, \mathrm{V}=$ Voltage Amplitude, $\mathrm{AF}=$ Antenna Factor, $\mathrm{dB} / \mathrm{m}$ and $\mathrm{L}=$ System Loss, $\mathrm{dB}$.

Voltage amplitude is the voltage received obtained from spectral analyzer or other instruments. Since the spectrum analyzer connected to an omni-directional antenna by a coaxial cable, thus the calculation must include the loss from the coaxial cable. Same goes to any type of cable used. While, antenna factor (AF) is the ratio of electric field strength at antenna to the voltage produce at antenna connector [27].

\subsection{Factors Influence the EM Radiation Exposure Levels}

Factors that influence the level of EMR exposure are the most important aspect for determining measurement techniques that are appropriate in this study. The radiation exposure level of BST depends on several factors such as: the distance from the radiation sources, the height of the tower, tilt and direction of the antennas fixed on the top of the tower, the number of antennas on single tower, the type of radiation pattern [22-24, 27], the direction of main beam of radiation, the feeding power and the operating frequency [32].

The radiation levels will enhance once an antenna is added on the Base Station Tower (BST) [2]. In the presence of multiple antennas on single tower, exposure level measurement for all the antennas must be considered. This is because the standard guideline limit of exposure level applies to the total power produced by all antennas [1].

Main lobe of radiation from antennas also influences the total exposure. The exposure from the main beam is higher than those from the side beam and also fluctuate according to the number of calls [33-34]. Normally, the power radiated from the side beam of an antenna is at 
least weaker than the main beam in hundred times therefore will not be a threat to public health. Previous study published analysis of the exposure levels of major cities in Sri Lanka and expected that the main beam from base station antennas to reach ground level, typically between 50 and $300 \mathrm{~m}$ from the foot of the antenna mast when the heights and the tilt of the antennas slightly downward are in consideration. Thus, the radiation level below $50 \mathrm{~m}$ of the mast is only due to any minor lobes which the exposure levels are very low [27]. Radiation power level will be higher in several kilo watts in the main beam direction and will be much lower when far away from the main beam [29].

Result obtained from a previous research, the maximum value of EMF energy flux density was recorded at a distance $55 \mathrm{~m}$ which is not from the tower but measured from the antenna. It is because the main beam radiation pattern of the antenna reached the ground surface at that distance [6]. However, from an observation, the radiation directly under the base station antennas which is usually less than $50 \mathrm{~m}$ was not always in zero value because of the mobile traffic of the base stations that always changing depends on the number of calls and causing the power densities fluctuate according to the number of calls. Otherwise, for those who living in the buildings at the same height of base station antennas, they are already in safety zone [27]. Since the main beam of the radiation pattern reached the ground surface, thus, the compliance distance that have the same height with the antenna is a direct distance and we called the beam pattern as side beam. Such in current study, EM radiation effects of BST can be reduced by increasing height of towers, changing the direction of antenna facing or relocating BST away from densely populated areas [30]. One of the phone companies in England is being forced to remove its cell towers by residents and local authorities when cancer rates in the building raised ten times above the national average [29].

Previous studies have decide to carry out all the measurements of radiation levels when there were no people using mobile phones or were not engaged in any activities involving the emission of radiation. In addition, the measurements started at the foot of the base station by assume $0 \mathrm{~m}$ as the first point by following the direction of the main beam of the antenna [33-34]. Therefore, the actual distance that must be measured to determine the exposure level from one source is the distance of antennas mounted on the top of the tower. Measuring the 
distance from the base of the tower is not proper. Therefore, the height of the tower and antenna tilt also must be considered as techniques to the radiation exposure level measurement.

Other than that, LOS path also is one of the factors that influence the exposure level. When signals do not travel in LOS path, the signal strength will be lower than signals which travel in LOS path. Based on the analysis of the results obtained from the past research, the transmission path of the radio wave which not propagates in LOS path was obstruct by buildings constructed. It is because the transmission of radio waves in that path is affected by the obstruction, which is influenced by its size and electrical properties has caused the signal strength lower than radio wave which propagate in LOS path [3]. Moreover, it also depends on the material of the building such intermediate materials which constructed by concrete and bricks. These physical objects were not only may exist as buildings but also trees, hills or mountains along the receiver and communication tower. Therefore, the incident waves also will be dependent on the electrical properties of the obstruction's material. Then, conductivity of the material will be considered. The exposure levels of the people nearby also depend on several factors such as reflection, diffraction and diffusion by physical [33-34]. These factors caused by radio waves incident on the buildings constructed also depending on their thickness and type of material [3]. With the existence of this obstruction, the received signal strength will be decreased because of the increase in path loss.

The incident wave transmit from the transmitter will unaffected when the size of the obstruction is smaller than the wavelength of the wave. Wave diffraction will occur around the obstruction when both have the same size while some of the wave may transmit through the obstruction. Such past study, towers are selected based on its accessibility and have good line of sight to the antennas. When radio waves travel in LOS path its meaning that the measurement was taken at a position that is clear without any blockage thus, the signal strength received and distance of the wave propagation is according to inverse square law [3]. According to the inverse square law, the power densities measured influenced by the distance from the antennas of the base stations [33]. 


\section{MEASUREMENT TECHNIQUES}

\subsection{Measurement Instrument}

Instrument that were often used to determine the exposure level is radiation field meter, power meter and spectrum analyzer. Generally, this instrument is used to measure the signal strength, power density and some other parameters base on the available functions on the particular instrument. However, the specifications of the instrument used must be compatible with the study. Since this study was to determine the EM exposure level at RF range, thus the instrument should be able to covers a frequency range up to $3 \mathrm{GHz}$ [5-6, 29, 33-34]. Mention about the advantages of using a spectrum analyzer, the power only in specific channel of the mobile device is supposed to be transmitting can be read and enables to measure power within more specified frequency bands. Many of the commonly used isotropic broadband meters, however it performs very poorly in this multi-signal environment. This instrument just enables for broadband frequency coverage and unsuitable for the carrier frequency associated with a power reading. Besides, the power meter just shows the total average power value and would be complicated when there are two or more strong signals present at the same time [29]. Thus, spectrum analyzer is more convenient and high sensitivity.

In addition, most of past studies were performed using isotropic (tri-axial) probes or antennas which usually mounted on field meter and spectrum analyzer [22-24, 32]. The tri-axial probe can capture the radio signal from all directions $(\mathrm{x}, \mathrm{y}, \mathrm{z})$ with different polarizations $[1,29]$. However, the efficiency of this manufactured probe not usually in high efficiency. This is because, wider bandwidth, low the efficiency. So that, used more specific antenna with high efficiency is more accurate. Generally, an antenna which is good in term of efficiency can radiates in between $50 \%$ to $60 \%$ of the energy fed to it.

\subsection{Techniques of Measurement}

Since the distance from the source of radiation is the main factor affecting the level of EM exposure, thus the measurement of distance from source is important before EM exposure level measurement began. The results of a survey conducted by [35] on 530 respondents (270 men, 260 women) showed that those who live at a distance up to $10 \mathrm{~m}$, most of them complain only experienced nausea, loss of appetite and visual disturbances while respondents 
who live at a distance up to $100 \mathrm{~m}$ from the base station to complain mostly irritability, depressive tendencies and lowering of libido. At a distance of $200 \mathrm{~m}$, they suffer from headaches, sleep disturbances and feeling of discomfort then followed by respondents who lived with the distance of $200 \mathrm{~m}$ to $300 \mathrm{~m}$, they are only the complaint of fatigue is experienced significantly more often. The observations were made in comparison with respondents who live at a distance of more than $300 \mathrm{~m}$ from the substation installation. Therefore, in [35] suggested that cellular phone base station should not closer than $300 \mathrm{~m}$ to the populations because every people have their own sensitivity to the exposure and the worst distances from cellular phone base stations is less than $100 \mathrm{~m}$.

Such the study conducted by past researcher, each measurement was repeated at increments of $10 \mathrm{~m}$ from the sources [36]. However, in another study, the measurement were taken at 10, 75 and $100 \mathrm{~m}$ from the radiation sources were chosen based on the real distance of the road, residential and educational areas around the measurement site [1].

Such in a study of broadband and narrowband measurement, compliance distance is not taken into account. In the study, broadband measurement on an area (zone A) was conducted [33-34]. Measurements were carried out at a total of 30 points which are in the range of zone A and point that has the highest power density was identified. Then, followed by narrowband measurement for more details on the frequency band GSM 900, GSM 1800 and UMTS. Afterwards, the highest power density (exposure level) for each frequency band was compared with MPE set by ICNIRP.

The compliance distance is also referred to as a safe distance [37]. It can be determined when one of the factors such as power density, field intensity and the SAR for the area around the base station is at a safe level by referring to the exposure limit set by government agencies and several organizations responsible. Areas that exceed the compliance distance is called compliance zone where this zone is treated as safer zone for general public. Besides that, zone which restricted access both to workers and the general public called exceedance zone while zone which is only allowed to workers known as occupational zone [4].

A given location which has high exposure level still in the compliance zone even no one will be exposed at that location. Due to the distance from the antennas, those locations right in 
front of the antennas may have significant radiation contribution and suggested that need to be restricted by control the distance to minimize the exposure to workers and general public especially those living in the area [2]. Besides that, transmitted power, antenna gain, frequency, antenna height, tilt is among the factors to be taken into account in determining compliance distance [4].

EM field measurements in the near and far zone of the communication antenna were conducted in a study [6]. Near field which is referred as reactive field is used to characterize the nature of an EM wave that is close to the source of radiation. The near field is not suitable to conduct the measurement because the electric and magnetic field strength are not perpendicular to each other, thus, it is difficult to relate both of them with a spreading EM wave. While far field which is referred as radiative field which the electric field, magnetic field and power density are combined together [29]. No wonder most of the studies used to far-field measurement to determine the far field measurements to determine level of EM exposure. Thus, when the far-field region can be reached, the EM field energy and power density can be calculated according to the formula below.

$\mathrm{S}=\mathrm{E} 2 / \mathrm{Zo}$ or $\mathrm{S}=\mathrm{Zo} \mathrm{H} 2$

where $\mathrm{S}=$ Power density, $\mathrm{W} / \mathrm{m}^{2}, \mathrm{E}=$ Electric field strength, $\mathrm{V} / \mathrm{m}(\mathrm{dB} \mu \mathrm{V} / \mathrm{m}$ in $\mathrm{dB}), \mathrm{H}=$ Magnetic field strength, $\mathrm{A} / \mathrm{m}(\mathrm{dB} \mu \mathrm{A} / \mathrm{m}$ in $\mathrm{dB})$ and $\mathrm{Zo}=$ Characteristic Impedance, $377 \Omega$.

Table 2. The appropriate measures based on the distance from the radiation source

\begin{tabular}{cc}
\hline Distance from Source & Measurement \\
\hline $0 \mathrm{~cm}$-about $5 \mathrm{~cm}$ & SAR measurement \\
$5 \mathrm{~cm}$-about $20 \mathrm{~m}$ & Electric and magnetic fields separately measure \\
About $20 \mathrm{~m}$ and beyond & Power density measurement \\
\hline
\end{tabular}

Such SAR measurement, near field conditions provide more realistic results which is suitable for measurements in laboratory environment. However, high number of measurements are required in order to enhance precision. Actual exposure below an antenna can be significantly less than far field exposure in many cases [2]. Unfortunately, the populations living in the 
vicinity of base stations are expose to the radiations in the far field [27].

\subsection{Techniques of Analysis and Data Presentation}

Usually, in the studies on electromagnetic radiation exposure from BST showed the calculated exposure level in terms of power level which estimated from distance to the BST. This assessment are extremely difficult and time consuming. Thus, map measurements in such study or project of electromagnetic pollution was suggested [38]. There are many recent studies have used mapping technique in presenting their data obtained from actual values [20, 29, 39-40]. Such a past research, the EM pollution measurement performed in crowded residential areas (actual values) was compared to the statistical model analysis (estimated values) [33-34]. Then, followed by digital maps processing for related places by embedded the values of EM field strength (EM pollution) values which obtained from measurement regions.

The study of GIS software has emerged in the last decade and has been chosen in various studies as the best technique due to its exciting multi-disciplinary endeavor, spanning such areas as geography, the environmental sciences and computer science $[38,40-42,44]$. Besides, GIS software is a scientific tool that incorporates geographical features with tabular data known as spatially referenced in order to map and analyze assess real-world problems by reference to locations on the earth [40]. GIS is often used together with Global Positioning System (GPS) are the most reliable method to identify and locate the various sources of EMF radiation [29]. These modern techniques have been applied to many applications to provide accurate positioning, data capturing, storing, organizing, managing, analyzing, retrieving and end ups with mapping and statistical modelling [20, 29, 40, 46]. GIS also is an automatic system that merges data and visualizes localized geographically information [42-45, 47]. In addition, NASA stated that GIS is a computer modelling system that allows for the integration and collective analysis of geo spatial data from multiple sources including satellite imagery, GPS recordings and textual attributes associated with a particular space (NASA).

Such in one of the EM study, the Natural Neighbour (NN) interpolation technique was applied by using the GIS (ArcGIS software's analyst module) so that the environmental EM pollution maps are produced [39]. Not only that, GIS can also be used as a method to indicate a 
correlation other than statistical methods. For example, GIS was applied in the other research to recognize the correlation between dengue distribution cases to the climatic factors in Cheras, Kuala Lumpur, Malaysia [38]. In GIS software, the interpolation is a process of estimating grid values using measured observations taken from a point. This technique can improve the understanding of the reader to understand more at the same the data presentation is able to compare clearly [33-34].

\section{CONCLUSION}

According to the review of existing scientific research, several aspects and methods need to be considered before conducting the measurement. Firstly, the selection of appropriate tools for the study which the equipment specifications is crucial to avoid errors in measurement. We can conclude that the use of spectrum analyzer is suitable for our future study since the signal power level in specific channel of the mobile device can be read and enables to measure power within more specified frequency bands. For instance, antennas used should cover radiofrequency of interest which is below $3 \mathrm{GHz}$ where the telecommunication activities fall in this range of frequency bands. Besides that, the research site should be determined before the study is performed in order to identify the factors that influence the level of exposure which may be caused by environmental conditions.

Furthermore, near field and far field should also be identified to determine the appropriate zone and distance to conduct the research. Finally, the data and results obtained could be analyzed and presented using mapping technique such as the Geographical Information System (GIS) using ArcGIS software for better interpretation.

\section{ACKNOWLEDGEMENTS}

This study is made possible by the usage of the grant FRGS (FRGS/1/2015/SG02/UNISZA/02/1), TPM (68006/2016/79), UMT (68006/INSENTIF/60), RACE-UNISZA (RACE/F1/ST1/UNISZA/15) and RACE-UM (CR0008-2015). 


\section{REFERENCES}

[1] Dawoud M M. High frequency radiation and human exposure. In International Conference on Non-Ionizing Radiation at UNITEN, 2003, pp. 1-7

[2] Robert F C, David M S, Jerry L U. Evaluating compliance with FCC guidelines for human exposure to radiofrequency electromagnetic fields. Washington D.C.: Federal Communications Commission, 1997

[3] Mahadi W N L, Ali N M, Wen Q P. Evaluation of RF EMF exposure pattern on selected communication towers in Malaysia. IEEE International Conference on Semiconductor Electronics, 2010, pp. 344-347

[4] Chitranshi R, Pancholi P. Analysis of cell tower radiations and practical realization of compliance distance. International Journal of Scientific and Research Publications, 2013, $3(5): 12-18$

[5] Durduran S S, Seyfi L, Avci C, Ozan A M. Measurement of electromagnetic signal strengths of four GSM base stations at $900 \mathrm{MHz}$ in a pilot region. In World Congress on Engineering, 2013, pp. 3-5

[6] Baltrenas P, Buckus R. Measurements and analysis of the electromagnetic fields of mobile communication antennas. Journal of Measurement, 2013, 46(10):3942-3949

[7] Shabani H, Islam M R, Alam A H M Z, El-Raouf H E A. EM radiation from Wi-LAN base station and its' effects in human body. In 5th IEEE International Conference on Electrical and Computer Engineering, 2008, pp. 86-91

[8] Medeiros L N, Sanchez T G. Tinnitus and cell phones: The role of electromagnetic radiofrequency radiation. Brazilian Journal of Otorhinolaryngology, 2016, 82(1):97-104

[9] Morgan L L, Kesari S, Davis D L. Why children absorb more microwave radiation than adults: The consequences. Journal of Microscopy and Ultrastructure, 2014, 2(4):197-204 [10] Xu S, Zhou Z, Zhang L, Yu Z, Zhang W, Wang Y, Wang X, Li M, Chen Y, Chen C, He M. Exposure to $1800 \mathrm{MHz}$ radiofrequency radiation induces oxidative damage to mitochondrial DNA in primary cultured neurons. Journal of Brain Research, 2010, 1311:189-196

[11] Camara P R S. Effect of exposure to non-ionizing radiation (electromagnetic fields) on the human system: A literature review. Journal of Interdisciplinary Histopathology, 2014, 
2(4):187-190

[12] Bahaodini A, Owjfard M, Tamadon A, Jafari S M. Low frequency electromagnetic fields long-term effects on testicular histology, sperm quality and testosterone levels of male rats. Asian Pacific Journal of Reproduction, 2015, 4(3):195-200

[13] Islam M T, Abidin H Z, Faruque M R I, Misran N. Analysis of materials effects on radio frequency electromagnetic fields in human head. Progress in Electromagnetics Research, 2012, 128:121-136

[14] Hayland G J. Physics and biology of mobile telephony. The Lancet, 2000, 356(9244):1833-1836

[15] Rothman K J. Epidemiological evidence on health risks of cellular telephones. The Lancet, 2000, 356(9244):1837-1840

[16] Elwood J M. Epidemiological studies of radio frequency exposures and human cancer. Bioelectromagnetics, 2003, 24(6):S63-S73

[17] Ahlbom A, Green A, Kheifets L, Savitz D, Swerdlow A. Epidemiology of health effects of radiofrequency exposure. Environmental Health Perspectives, 2004, 112(17):1741-1754

[18] Kundi M, Mild K, Hardell L, Mattsson M. Mobile telephones and cancer-A review of epidemiological evidence. Journal of Toxicology and Environmental Health, Part B, 2004, $7(5): 351-384$

[19] Sadetzki S, Chetrit A, Jarus-Hakak A, Cardis E, Deutch Y, Duvdevani S, Zultan A, Novikov I, Freedman L, Wolf M. Cellular phone use and risk of benign and malignant parotid gland tumors-A nationwide case-control study. American Journal of Epidemiology, 2008, 167(4):457467

[20] Durduran S S, Uygunol O, Seyfi L. Mapping of electromagnetic pollution at $1800 \mathrm{MHz}$ GSM (global system for mobile communication) frequency in Konya. Scientific Research and Essays, 2010, 5(18):2664-2672

[21] Yong C Y, Rahman T A, Chew K M. Wireless industry emission: Electromagnetic field monitoring and analysis. ARPN Journal of Engineering and Applied Sciences, 2015, 10(20):9800-9807

[22] International Commission on Non-ionizing Radiation Protection (ICNIRP). Home. 2017, 
http://www.icnirp.org/en/home/home-read-more.html

[23] International Commission on Non-ionizing Radiation Protection (ICNIRP). Base station:

High frequency. 2017, http://www.icnirp.org/en/applications/base-stations/index.html

[24] International Commission on Non-ionizing Radiation Protection (ICNIRP). Base station (high frequency): Characteristics of the application and its use. 2017, http://www.icnirp.org/en/applications/base-stations/index.html

[25] Malaysian Communication and Multimedia Commission (MCMC). Communications and Multimedia Act 1998: Commission determination on the mandatory standard for electromagnetic field emission from radio communications infrastructure-Determination no. 1, 2010,

https://www.mcmc.gov.my/skmmgovmy/files/attachments/Mandatory\%20Std\%20for\%20EM F\%20Det\%20No\%20\%201\%20of\%202010.pdf

[26] Malaysian Communications and Multimedia Commission (MCMC). Spectrum plan. 2014, https://www.mcmc.gov.my/skmmgovmy/media/General/pdf/Spectrum-Plan-2017i.pdf [27] Karunarathna M A A, Dayawana I J. Human exposure to RF radiation in Sri Lanka. Sri Lankan Journal of Physics, 2005, 6:19-32

[28] Sukhdeep K, Jaipreet K, Manjit S. Effects of mobile radiations and its prevention. International Journal of Computer Science and Mobile Computing, 2016, 5(2):298-304

[29] Al-Akhras M A, Albiss B A, Alqudah M S, Odeh T S. environmental pollution of cell-phone towers: Detection and analysis using geographic information system. Jordan Journal of Earth and Environmental Sciences, 2015, 7(2):77-85

[30] Sivani S, Sudarsanam D. Impacts of radio-frequency electromagnetic field (RF-EMF) from cell phone towers and wireless devices on biosystem and ecosystem-A review. Biology and Medicine, 2012, 4(4):202-216

[31] Urbinello D, Joseph W, Huss A, Verloock L, Beekhuizen J, Vermeulen R, Martens L, Roosli M. Radio-frequency electromagnetic field (RF-EMF) exposure levels in different European outdoor urban environments in comparison with regulatory limits. Environment International, 2014, 68:49-54

[32] Voudouris K, Grammatikakis P. Electromagnetic radiation measurements at aperture 
antennae installation sites. 5th WSEAS International Conference on Applied Informatics and Communications, 2005, pp. 419-424

[33] Ismail A, Din N M, Jamaluddin M Z, Balasubramaniam N. Electromagnetic assessment for mobile phone base stations at major cities in Malaysia. In 9th IEEE Malaysia International Conference on Communications, 2009, pp. 150-153

[34] Ismail A, Din N M, Jamaludin M Z, Balasubramaniam N. Mobile phone base station radiation study for addressing public concern. American Journal of Engineering and Applied Sciences, 2010, 3(1):117-120

[35] Satini R, Santini P, Le Ruz P, Danze J M, Seigne M. Survey study of people living in the vicinity of cellular phone base stations. Electromagnetic Biology and Medicine, 2003, 22(1):41-49

[36] Keow M A, Radiman S. Assessment of radiofrequency/microwave radiation emitted by the antennas of rooftop-mounted mobile phone base stations. Radiation Protection Dosimetry, 2006, 121(2):122-127

[37] Mortazavi S M, Mortazavi S A. Tinnitus and cell phones: The role of electromagnetic radiofrequency radiation. Brazilian Journal of Otorhinolaryngology, 2016, 82(2):248-249.

[38] Mustafa A D, Azid A, Juahir H, Amran M A, Kamarudin M K A, Gasim M B. Geographical Information System (GIS) for relationship between dengue disease and climatic factors at Cheras, Malaysia. Malaysian Journal of Analytical Sciences, 2015, 19(6):1318-1326 [39] Genc Ä O, Bayrak M, Yaldz E. Analysis of the effects of GSM bands to the electromagnetic pollution in the RF spectrum. Progress in Electromagnetics Research, 2010, $101: 17-32$

[40] Moraru L, Marica L. Necessity of GIS system for electromagnetic field management in Galati. Journal of Science and Arts, 2011, 1(14):85-90

[41] Gumusay M U, Sen A, Bulucu U, Kavas A. Electromagnetic coverage calculation in GIS. In International Symposium on Mobile Mapping Technology, 2007, pp. 1-6

[42] Toriman M E, Abdullah S N F, Azizan I A, Kamarudin M K A, Umar R, Mohamad N. Spatial and temporal assessment on drug addiction using multivariate analysis. Malaysian Journal of Analytical Science, 2015, 19(6):1361-1373 
[43] Kamarudin M K A, Toriman M E, Rosli M H, Juahir H, Aziz N A A, Azid A, Zainuddin S F M and Sulaiman W N A. Analysis of meander evolution studies on effect from land use and climate change at the upstream reach of the Pahang River, Malaysia. Journal Mitigation and Adaptation Strategies for Global Change, 2015, 20(8):1319-1334

[44] Kamarudin M K A, Toriman M E, Rosli M H, Juahir H, Umar R, Sulaiman N H, Ata F M, Mustafa A D, Amran M A, Yusoff W A, Azaman F. Assessment of river plan change using RS and GIS technique. Jurnal Teknologi, 2015, 76(1):31-38

[45] Ismail A, Toriman M E, Juahir H, Zain S M, Habir N L A, Retnam A, Kamarudin M K A, Umar R, Azid A. Spatial assessment and source identification of heavy metals pollution in surface water using several chemometric techniques. Journal Marine Pollution Bulletin, 2016, 106(1-2):292-300

[46] Sen A, Gümüsay M U, Kavas A, Bulucu U. Programming an artificial neural network tool for spatial interpolation in GIS-A case study for indoor radio wave propagation of WLAN. Sensors, 2008, 8(9):5996-6014

[47] Umar R, Sabri N H, Abidin Z Z, Ibrahim Z A. How to deal with radio astronomy interference. Publications of the Korean Astronomical Society, 2015, 30(2):691-693

\section{How to cite this article:}

Author A family name followed by intials of his/her first name, Author B and Author C (should be written in the same manner). Article title. J. Fundam. Appl. Sci., 2017, 9(2S), 182-198. 